\title{
AS ESTRUTURAS ARQUEOLÓGICAS DO ALTO PARANAÍBA E TRIÂNGULO MINEIRO — MINAS GERAIS
}

\author{
Marcia Angelina Alves*
}

\begin{abstract}
ALVES, M. A. As estruturas arqueológicas do Alto Paranaiba e Triângulo Mineiro - Minas Gerais. Rev. do Museu de Arqueologia e Etnologia. S. Paulo, 2:27-47, 1992.
\end{abstract}

RESUMO: O presente artigo apresenta as estruturas arqueológicas (associadas à estratigrafia $e$ às dataçōes) das regiōes do ALTO PARANAÍBA e TRIÂNGULO MINEIRO, Estado de Minas Gerais, detectadas e evidenciadas pelo projeto de pré-história "QUEBRA ANZOL", criado em 1980. Este projeto baseia-se na execução de um programa de PROSPECÇŌES e ESCAVAÇŌES sistemáticas que, em doze anos de pesquisa, possibilitou escavar seis sítios arqueológicos - PRADO, SILVA SERROTE, INHAZINHA, REZENDE, MENEZES e RODRIGUES FURTADO, objetivando a obtenção de uma ampla visão da arqueologia do Vale do Paranaiba, Minas Gerais.

UNITERMOS; Vestígios. Estratigrafia. Dataçōes. Estruturas. Superfícies Amplas. Padrōes de Assentamento.

\section{Introdução}

As pesquisas arqueológicas desenvolvidas nas regiōes do ALTO PARANAÍBA e TRIÂNGULO MINEIRO, Estado de Minas Gerais, iniciaram-se em 1980 com a criação do Projeto QUEBRA ANZOL, o qual empreende um programa sistemático de PROSPECÇŌES e ESCAVAÇŌES no vale do Paranaiba (Alves, 1991a).

Iniciaram-se em terrenos do Municipio de Perdizes, vale do Quebra Anzol (subafluente do Paranaiba) por ter sido a primeira cidade a coletar vestígios (urna funerária, tigelas, potes,

(*) Museu de Arqueologia e Etnologia da Universidade de São Paulo. mãos-de-pilão, lâminas de machado polidas, raspadores, etc.), quando de realizaçōes de aragens do solo, para a plantação de culturas temporárias e permanentes e para a criação de pastos destinados à alimentação de gado bovino.

Assim, estes testemunhos indicaram artefatos confeccionados por populações que sabiam trabalhar a pedra (lascamento e polimento), conheciam a técnica de modelar a argila, produziam cerâmica utilitária e funerária, dominavam o fogo e já haviam desaparecido sem deixar escrita.

Informaçōes orais de fazendeiro e agregado que coletaram os achados acima mencionados facilitaram a detecção do sítio PRADO, através de prospecção realizada na fazenda Engenho Velho, a $15 \mathrm{~km}$ de Perdizes (Mapa 1). Este sitio foi o primeiro a ser escavado. Nele foram desenvolvidas três campanhas: julho- 
ALVES, M. A. As estruturas arqueológicas do Alto Paranaiba e Triângulo Mineiro - Minas Gerais. Rev. do Museu de Arqueologia e Etnologia, S. Paulo, 2:27-47, 1992.

1980/81/83 (Alves, 1982), (Alves, 1983/84), (Alves, 1988), (Alves, 1991b) e (Alves e Girardi, 1989).

Em 1984/85 o programa do Projeto Quebra Anzol ampliou-se estendendo a pesquisa ao Municipio de GUIMARÂNIA, vale do Espirito Santo (afluente do Paranaiba), com o desenvolvimento de prospeç̧ão e escavação no sitio SILVA SERROTE, distante, aproximadamente, $9 \mathrm{~km}$ da sede municipal (Mapa 1), (Alves, 1988) e (Alves, 1991b).

Sofreu nova ampliação em $1988 \mathrm{com}$ a detecção e realização da primeira campanha no sitio REZENDE (vales do Piedade e Paranaiba - divisa com o Estado de Goiás), fazenda do Paiolão $7 \mathrm{~km}$ de CENTRALINA que, no decorrente ano (1992), sofrerá a quinta campanha de pesquisa de campo (Mapa 1), (Alves, 1991a).

Em 1988 a pesquisa foi retomada em jazidas arqueológicas situadas no municipio de PERDIZES, com a escavação do sitio INHAZINHA, localizado na fazenda Água Limpa, distante $25 \mathrm{~km}$ da sede municipal (Mapa 1), (Alves, 1991a).

No ano de 1991 escavou-se o sítio MENEZES, localizado na fazenda São Francisco do Borja, a $9 \mathrm{~km}$ de Perdizes (Mapa 1), (Alves, 1991a).

Em julho/agosto de 1992 desenvolveu-se a primeira campanha de pesquisa no sitio RODRIGUES FURTADO, em terrenos da fazenda Morro da Mesa, a $14 \mathrm{~km}$ da sede municipal (Mapa 1).

Assim, em doze anos de realizações de pesquisas no vale do Paranaiba escavaram-se seis sitios, encontrando-se dois, REZENDE e RODRIGUES FURTADO, em processo de pesquisa.

Os sítios escavados pelo Projeto Quebra Anzol são sitios a céu aberto encaixando-se no padrão de assentamento "LITO-CERÂMICO COLINAR", ${ }^{1}$ situando-se em encostas médias de colinas e em um chapadão, tendo em suas bases córregos e rios.

Nas escavaçōes em questão empregou-se o método de "SUPERFICIES AMPLAS" associada à "técnica de decapagens por niveis

(1) Configurado por Pallestrini (1975) em escavações desenvolvidas no Vale do Paranapanema, Estado de São Paulo, no âmbito do Projeto "Paranapanema". naturais" de Leroi-Gourhan (1950 e 1983), adaptado ao solo tropical do Brasil por Pallestrini (1975).

As escavações, centradas em método sistemático e criterioso de coleta de documentação arqueológica com controle estratigráfico, evidenciaram solos de ocupaçōes CERAMISTAS, representadas por populaçōes de HORTICULTORES e ocupaçōes LITICAS, de CAÇADORES-COLETORES.

\section{Ocupações e cronologia}

Executaram-se PERFIS estratigráficos nos sitios pesquisados e em processo de pesquisa que indicaram e indicam, até o presente, a ocorrência de:

- Um ÚNICO nivel arqueológico - o LITO-CERÂMICO com camada da superfície até $25 / 30 / 35 / 40 \mathrm{~cm}$ de profundidade para os sítios Prado, Silva Serrote, Inhazinha, Menezes e Rodrigues Furtado, representado por ocupaçōes de populaçōes ceramistas/horticultoras. (Fotos $1 \mathrm{e}$ 2).

Datação deste nivel, de carvão procedente do sítio Silva Serrote, coletado na Fogueira $_{1}$, na Mancha ${ }_{1}$ (Mapa 3), processada na França ${ }^{2}$ resultou em $670 \pm 50$ anos antes do Presente $^{3}$ (Gif-sur-Yvette).

- Um nível LITO-CERÂMICO para o sitio Rezende com depósitos em suas duas zonas de escavação (Mapa 8 e 9) mas, a datação efetuada pelo $\mathrm{CENA}^{4}$, corresponde apenas à

(2) As dataçōes processadas na França, no Laboratoire de Faibles Radioactivités, Gif-sur-Yvette, foram realizadas pelo projeto franco-brasileiro "Pré-história e Paleoambiente em Mato Grosso, bacia do Paraná", pelo coordenador francês, o pesquisador Denis Vialou, do Muséum National d'Histoire Naturelle.

(3) As dataçōes dos sitios Prado e Inhazinha estão sendo processadas por termoluminescência e a dos sítios Menezes e Rodrigues Furtado por Carbono 14.

(4) Centro de Energia Nuclear na Agricultura, Universidade de São Paulo, Campus de Piracicaba, que processou datações por $C_{14}$ financiadas pela FAPESP, em 1991, pelo projeto "Datação radiocarbônica de amostras de carvão provenientes de pesquisas arqueológicas do MAE/USP" (Scatamacchia e Alves), cujo financiamento foi solicitado pela pesquisadora Maria Cristina Mineiro Scatamacchia em um projeto que envolveu mais três pesquisadores: Marcia Angelina Alves, Luiz Carlos Ruiz Pessenda e Pli- 
ALVES, M. A. As estruturas arqueológicas do Alto Paranaiba e Triângulo Mineiro - Minas Gerais. Rev. do Museu de Arqueologia e Etnologia, S. Paulo, 2:27-47, 1992.

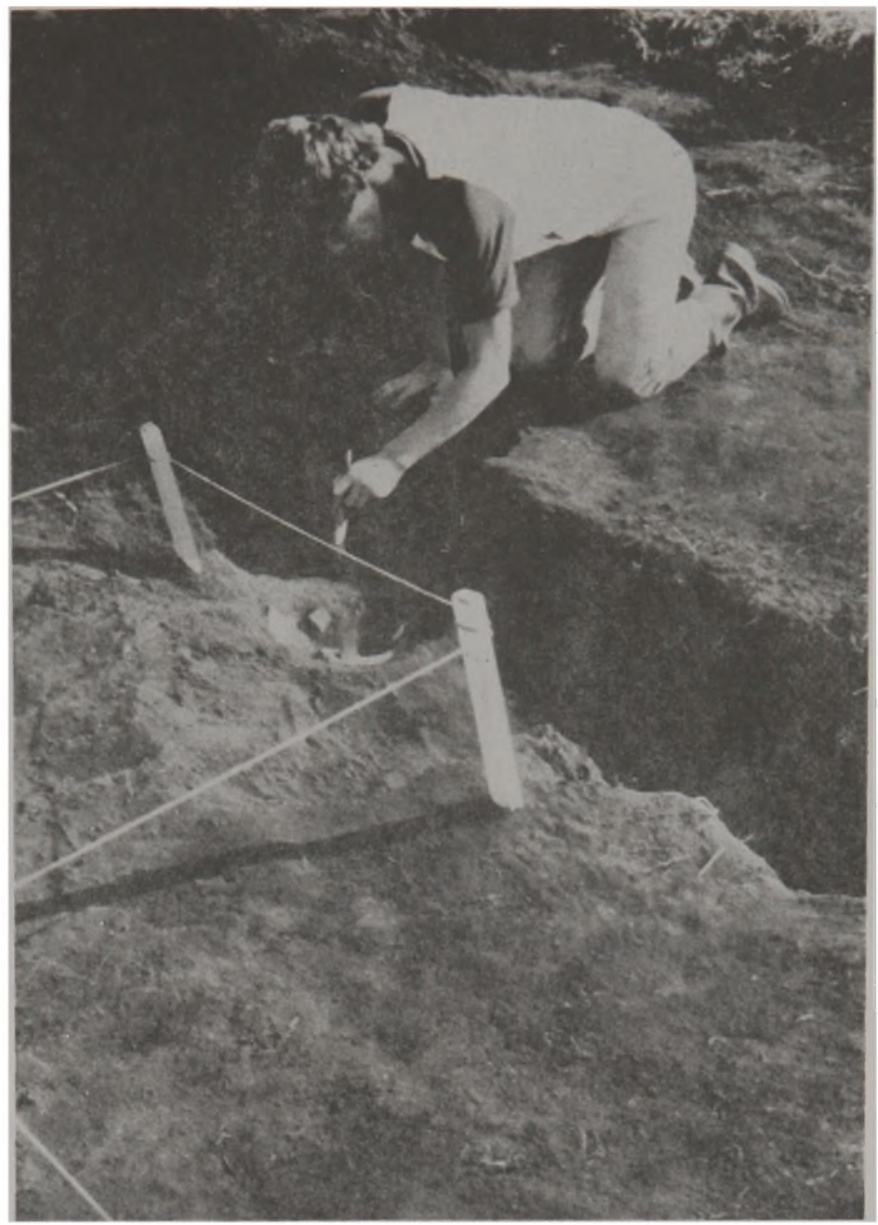

Foto 1 - Sítio PRADO - Evidenciação de um vaso cerâmico liso, no Perfil, executado junto à Mancha.

ocupação cerâmica da Zona ${ }_{2},{ }^{5}$ cujo carvão foi coletado na estrutura de combustão em volta do sepultamento ${ }_{1}-s_{1}$ (Mapa 9), que é de 1.190 60 anos antes do Presente (CENA);

- Niveis LÍTICOS SUPERPOSTOS para o sítio Rezende com faixas temporais distintas nas duas zonas de escavação, ou seja:

Zona $_{1}$ :

- Fogueira $_{1}-F_{1}$ - localizada a $90 / 100 \mathrm{~cm}$ de profundidade, associada a um bloco de

nio Barbosa de Camargo, sendo os dois últimos da Seção de Radionuclideos Naturais do CENA.

(5) A dataçāo da ocupaçāo cerâmica da Zona, está sendo processada por termoluminescência. quartzito, datada em $4.250 \pm 50$ anos a.P. (Gif.-sur-Yvette), (Mapa 8);

- Fogueira ${ }_{2}-F_{2}$ - situada a $110 / 120 \mathrm{~cm}$ de profundidade, cuja datação resultou em $4.950 \pm 70$ anos a.P. (CENA), (Mapa 8);

\section{Zona 2 :}

- Fogueira ${ }_{1}-F_{1}$ - localizada a $85 \mathrm{~cm}$ de profundidade, resultou em $5.620 \pm 70$ anos a.P. (CENA), (Mapa 9);

- Fogueira $_{3}-F_{3}$ - situada a $95 \mathrm{~cm}$ de profundidade, resultou em $6.110 \pm 70$ anos a.P. (CENA), (Mapa 9);

- Fogueira ${ }_{2}-F_{2}$-localizada a $100 / 105 \mathrm{~cm}$ de profundidade, cuja datação deu o resultado de $6.950 \pm 80$ anos a.P. (CENA), (Mapa 9); 
ALVES, M. A. As estruturas arqueológicas do Alto Paranaiba e Triângulo Mineiro - Minas Gerais. Rev. do Museu de Arqueologia e Etnologia, S. Paulo, 2:27-47, 1992.

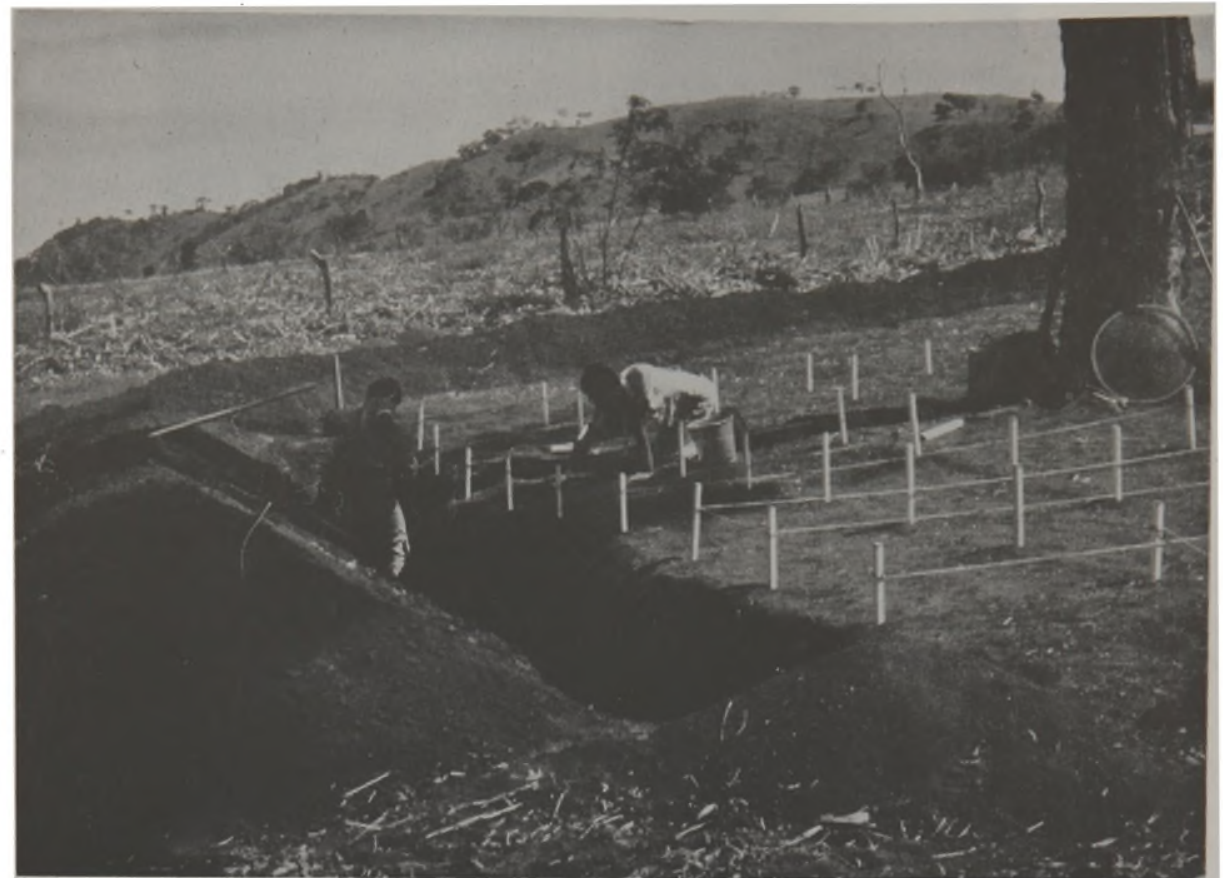

Foto 2 - Sítio SILVA SERROTE - Execução do Perfil 1 e realização de decapagens por niveis naturais na Mancha ${ }_{1}$.

- Fogueira $_{4}-\mathrm{F}_{4}$ - localizada a $125 / 130 \mathrm{~cm}$ de profundidade, junto ao Perfil 1 , associada a lítico, resultou na datação mais antiga$7.300 \pm 80$ anos a.P. (CENA), (Mapa 9), (Foto 3).

Os niveis líticos superpostos, datados, correspondem a ocupaçōes de populaçōes caçadoras/coletoras.

\section{Estruturas}

A definição de ESTRUTURA no quadro conceitual da ARQUEOETNOLOGIA - fundado em pesquisas realizadas na França e no Brasil - baseia-se na disposição de diferentes vestígios, que se agrupam, de maneira significativa, no contexto arqueológico de um sítio; subdivide-se em duas categorias: "SUPRAESTRUTURAS" e "INFRA-ESTRUTURAS" (Pallestrini, 1972/73).

As escavaçōes desenvolvidas nos seis sítios escavados e em processo de escavação detectaram, evidenciaram e evidenciam as seguintes ESTRUTURAS:
- de HABITAÇÃO - denominadas "Manchas Escuras" ou "Manchas de Terra Preta", resultantes da decomposição de antigas cabanas, que representam espaços habitacionais de ocupações ceramistas do nivel lito-cerâmico. Obtiveram-se as seguintes na especificidade de cada sítio:

- PRADO - em uma área de $4.800 \mathrm{~m}^{2}$ $(80 \times 60 \mathrm{~m})$ evidenciaram-se SETE Manchas Escuras (Mapa 2);

- SILVA SERROTE - em uma superfície de $5.000 \mathrm{~m}^{2}(100 \times 50 \mathrm{~m})$ evidenciaram-se TRINTA Manchas Escuras (Mapa 3);

- INHAZINHA - em um quadriculamento de $1.500 \mathrm{~m}^{2}(50 \times 30 \mathrm{~m})$ evidenciaram-se QUATRO Manchas Escuras (Mapa 5), (Foto 4);

- MENEZES - em uma superfície de $1.850 \mathrm{~m}^{2}(50 \times 37 \mathrm{~m})$ evidenciaramse QUATRO Manchas Escuras (Mapa 6),(Foto 5).

- RODRIGUES FURTADO - na realização da primeira campanha de es- 
ALVES, M. A. As estruturas arqueológicas do Alto Paranaíba e Triângulo Mineiro - Minas Gerais. Rev. do Museu de Arqueologia e Etnologia, S. Paulo, 2:27-47, 1992.

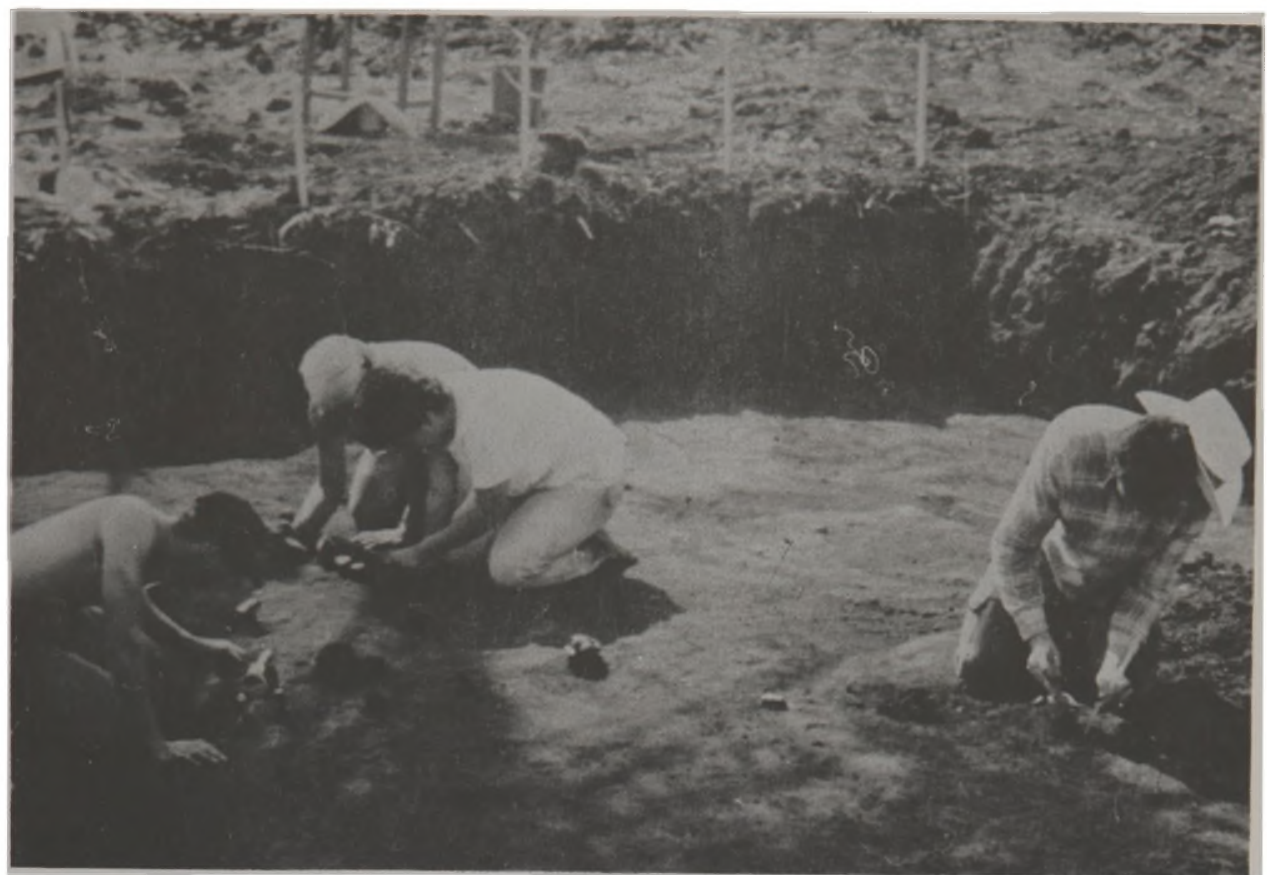

Foto 3 - Sítio REZENDE - Zona 2 - Desenvolvimento de decapagens no nivel lítico mais antigo (7.300 \pm 80 anos a.P.) em fogueira associada a lascas retocadas e raspadores.

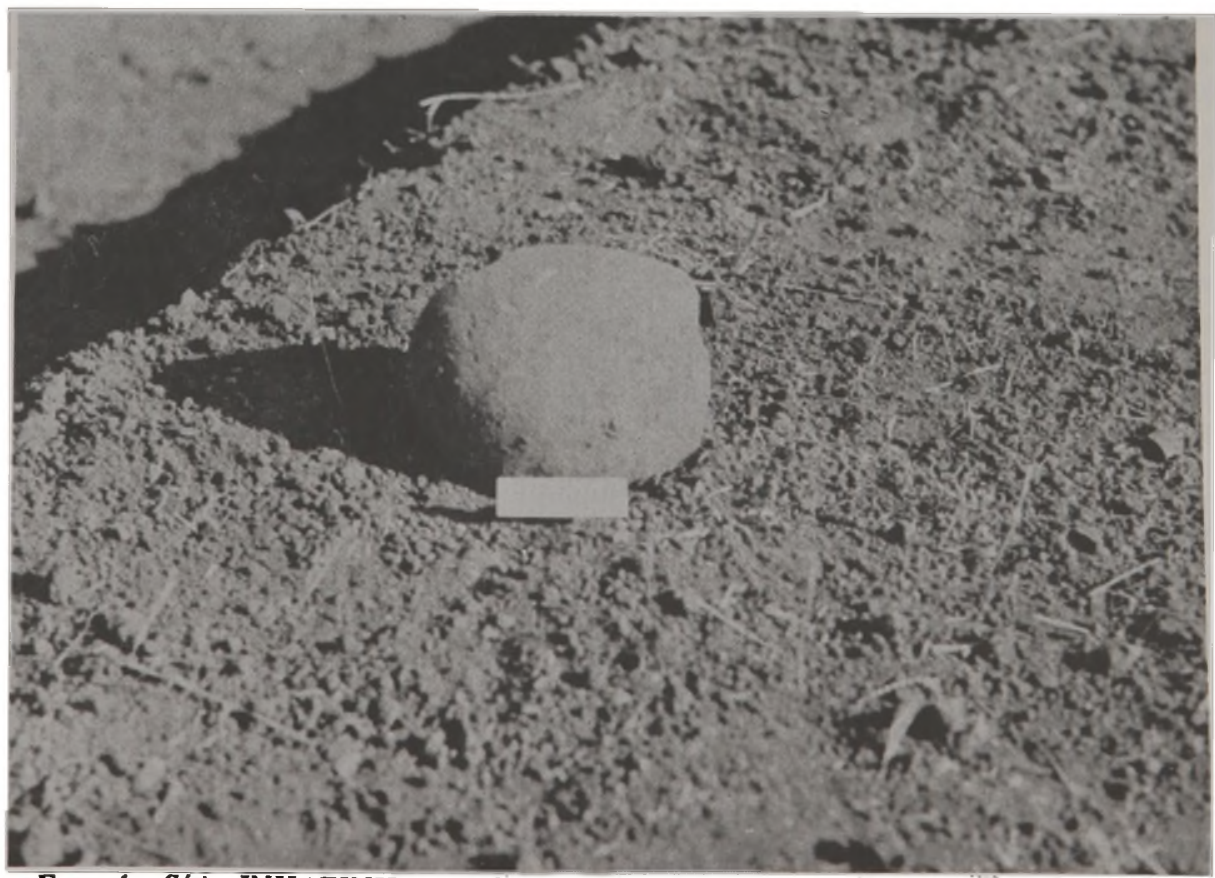

Foto 4 - Sítio INHAZINHA - Coleta de um pequeno pote, liso, na Trincheira 3. 
ALVES, M. A. As estruturas arqueológicas do Alto Paranaiba e Triângulo Mineiro - Minas Gerais. Rev. do Museu de Arqueologia e Etnologia, S. Paulo, 2:27-47, 1992.

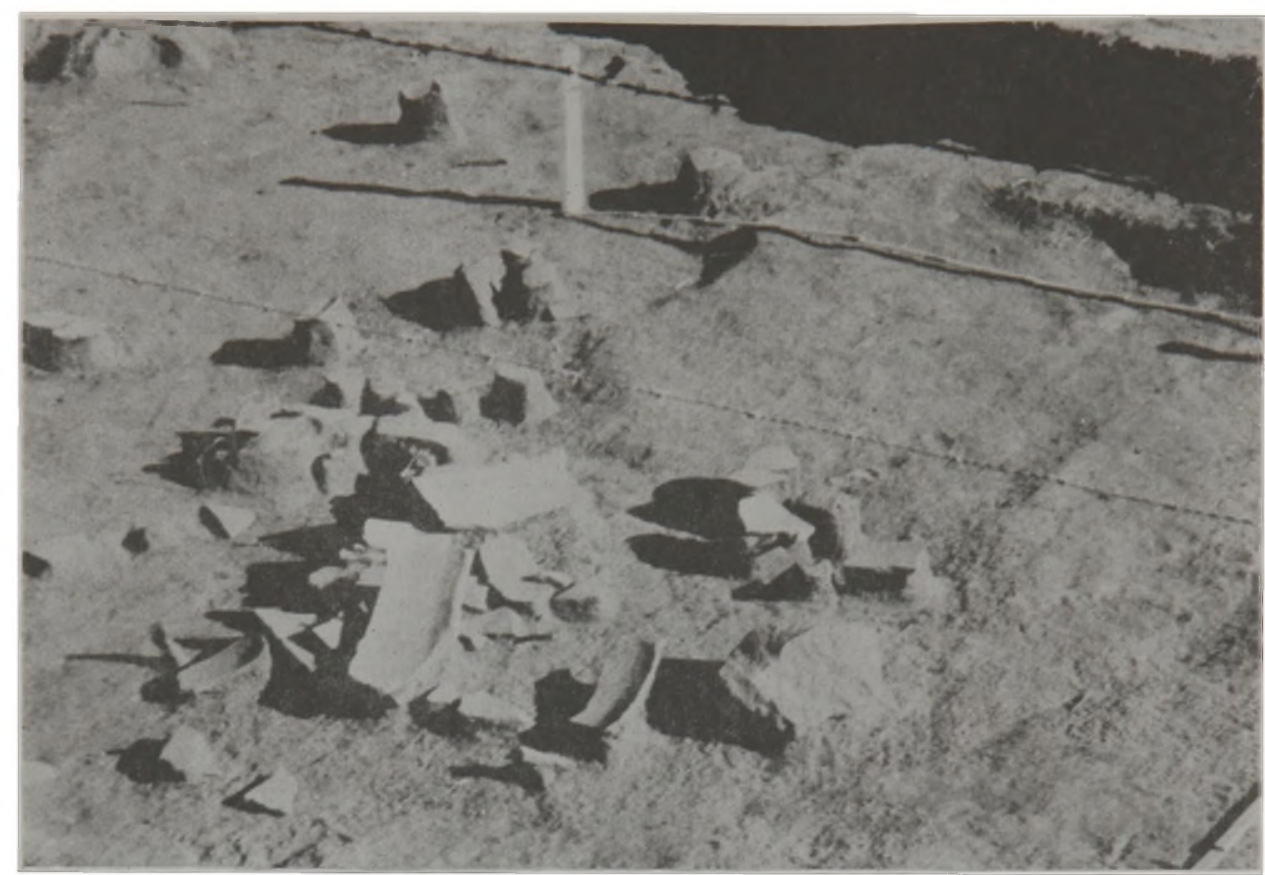

Foto 5 - Sítio MENEZES - Evidenciação de solo decapado - Mancha ${ }_{3}$, com destaque de um bloco debitado em arenito silicificado.

cavação, pesquisou-se em uma área de $1.750 \mathrm{~m}^{2}(50 \times 35 \mathrm{~m})$, evidenciando-se CINCO Manchas Escuras (Mapa 7); (Foto 6)

- REZENDE - em uma superficie de $23.720 \mathrm{~m}^{2}$ dividida em duas zonas de escavação detectou-se em cada uma o que se segue:

Zona $_{1}$ : área de $5.000 \mathrm{~m}^{2}(10 \times 50 \mathrm{~m})$ SEIS Manchas Escuras (Mapa 8);

Zona $_{2}$ : área de $18.720 \mathrm{~m}^{2}(156 \mathrm{x}$ $120 \mathrm{~m})$, TRES Manchas Escuras (Mapa 9)

- de COMBUSTÃO - evidenciadas em distintos contextos e níveis arqueológicos. São as abaixo descritas:

- ocorrência de carvão de madeira queimada em volta de um fundo de urna funerária ${ }^{6}$ no sítio Inhazinha (Mapa 5) e, em torno de um sepul-

(6) A urna funerária com sepultamento de um individuo em posição fetal foi retirada pelo proprietário da fazenda Água Limpa, Sr. José Palmieri, em 1975. tamento em decúbito lateral esquerdo, no sítio Rezende, Zona 2 , evidenciado na terceira campanha (1990), (Mapa 9);

- ocorrência de fogueiras circulares, INTERNAS às Manchas Escuras, nivel lito-cerâmico, detectadas nos sítios Prado $\left(\mathrm{M}_{3}-\mathrm{F}_{1}\right)$, Silva Serrote $\left(M_{1}-F_{1}\right)$ e Rodrigues Furtado $\left(M_{1}-F_{3}-\right.$ $\mathrm{F}_{4}$ ), (Mapas 2,3 e 7), (Foto 7);

- ocorrência de fogueiras circulares EXTERNAS às habitaçōes, nivel lito-cerâmico, em áreas de circulação nos sítios Prado $\left(\mathrm{T}_{4}-\mathrm{F}_{2}\right.$ associada a um bolsāo de lascamento - $\mathrm{B}_{2}$ ), Menezes $\left(\mathrm{T}_{6}-\mathrm{F}_{1}\right)$ e Rodrigues Furtado ( $T_{1}-F_{2}-F_{1}-$ associada a lítico), (Mapas 2, 6 e 7);

- ocorrência de fogueiras circulares nos níveis líticos superpostos da Zona $_{1},\left(\mathrm{~T}_{10}-\mathrm{F}_{1}\right)$ associada a um bloco de quartzito e $\left.T_{11}-F_{2}\right)$ e da Zona ${ }_{2}\left(T_{2}\right.$ $F_{I}$ associada a lítico, $T_{1}-F_{2}, T_{1}-F_{3}, T_{2}-$ $\mathrm{F}_{4}$ associada a lítico e $\mathrm{T}_{5}-\mathrm{F}_{5}-\mathrm{F}_{6} \mathrm{eF}_{7}$ ), (Foto 3). 
ALVES, M. A. As estruturas arqueológicas do Alto Paranaiba e Triângulo Mineiro - Minas Gerais. Rev. do Museu de Arqueologia e Etnologia, S. Paulo, 2:27-47, 1992.

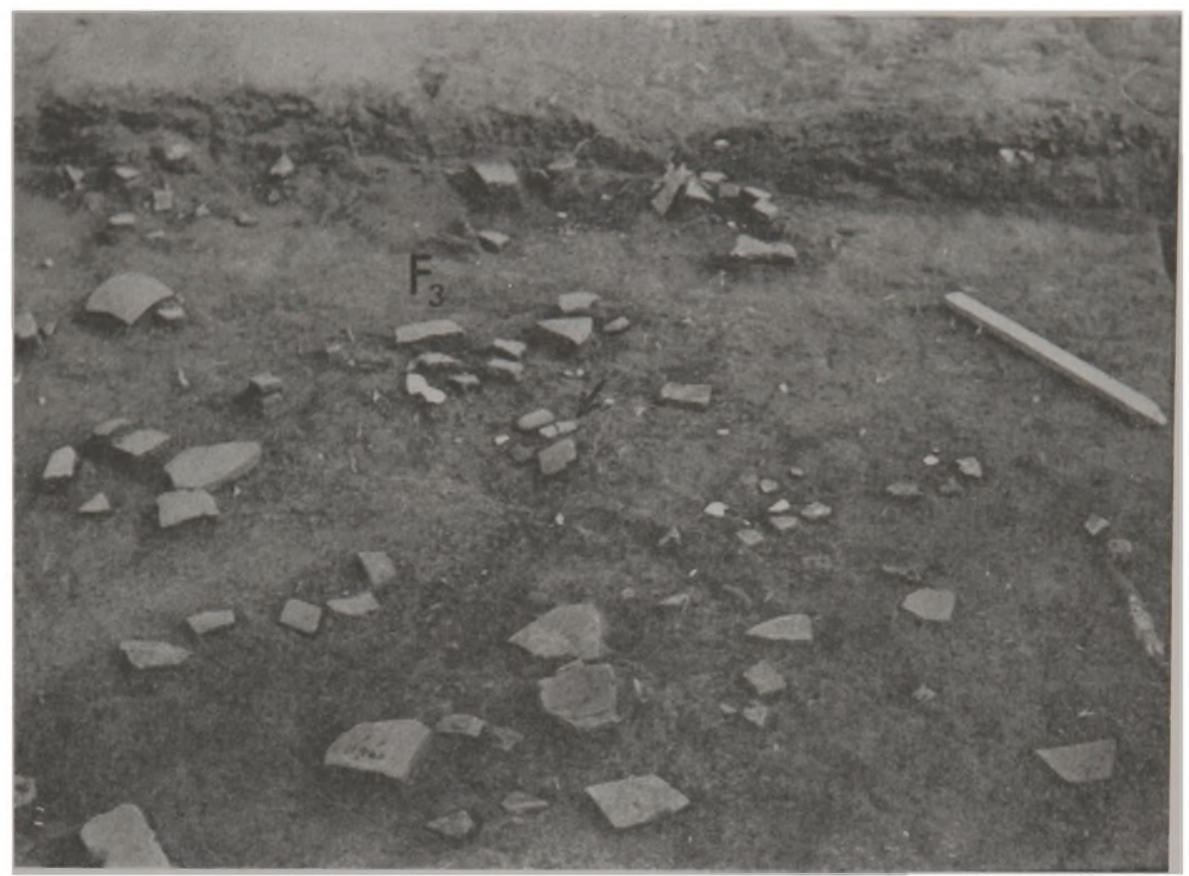

Foto 6 - Sítio RODRIGUES FURTADO - Solo decapado - Mancha ${ }_{1}$ com evidenciação de cerâmica e lítico destacando-se uma pequena mäo-de-piläo, fragmentada, associada à Fogueira 3.

- FUNERÁRIAS - representadas pela evidenciação de sepultamentos primários em dois niveis:

- em posição fetal, depositado em urnas de cerâmica lisa com tampa, fora dos espaços habitacionais mas na área da aldeia. Foram detectados nos sitios Silva Serrote e Inhazinha (Mapas 4 e 5);

- em decúbito lateral esquerdo com membros superiores e inferiores fletidos, evidenciado no sítio Rezende, Zona $_{2}$, associado a uma estrutura de combustão.

- de LASCAMENTO - foram evidenciadas as seguintes:

- ocorrência de um núcleo de tamanho médio, em quartzo, remontável com quatro peças e associado a onze residuos de lascamento, evidenciado no sítio Prado, Mancha ${ }_{1}$, setor C6 - 4a Decapagem (Alves, 1982), (Foto 8);

- ocorrência de grandes blocos debitados, correspondentes a núcleos em quartzo e arenito silicificado associados a lascas (sem retoques e retocadas) remontáveis, detectados no sitio Rodrigues Furtado, nas $\mathbf{M}_{2}$ e $\mathbf{M}_{5}$ 1ํ Decapagem e de um bloco debitado em arenito silicificado no sitio Menezes na $\mathbf{M}_{3}$ (Foto 5);

- ocorrència de peças liticas lascadas associadas a fogueiras circulares internas às habitaçōes, evidenciadas nos sitios Silva Serrote $\left(\mathrm{M}_{1}-\mathrm{F}_{1}\right)$ e Rodrigues Furtado $\left(\mathrm{M}_{1}-\mathrm{F}_{3}-\mathrm{F}_{4}\right) . \mathrm{Na}_{3} \mathrm{~F}_{3}$ do último sitio evidenciou-se além de lascas retocadas e sem retoque uma pequena mão-de-pilão, ou seja, um artefato em lítico polido (Foto 6);

- ocorrência de litico - lascas (retocadas e sem retoques), pontas e raspadores associados a fogueiras circulares em niveis liticos do sítio $\mathrm{Re}$ zende, Zona $2\left(\mathrm{~T}_{2}-\mathrm{F}_{1}\right.$ e $\left.\mathrm{T}_{2}-\mathrm{F}_{4}\right)$;

- de CONCENTRAÇÃO DE LASCA$M E N T O$ - ocorrência de bolsōes de lascamento nos sítios Prado $\left(\mathrm{T}_{1}-\mathrm{B}_{1}\right.$ e $\mathrm{T}_{4}-\mathrm{B}_{2}$ - associado a 
ALVES, M. A. As estruturas arqueológicas do Alto Paranaiba e Triângulo Mineiro - Minas Gerais. Rev. do Museu de Arqueologia e Etnologia, S. Paulo, 2:27-47, 1992.

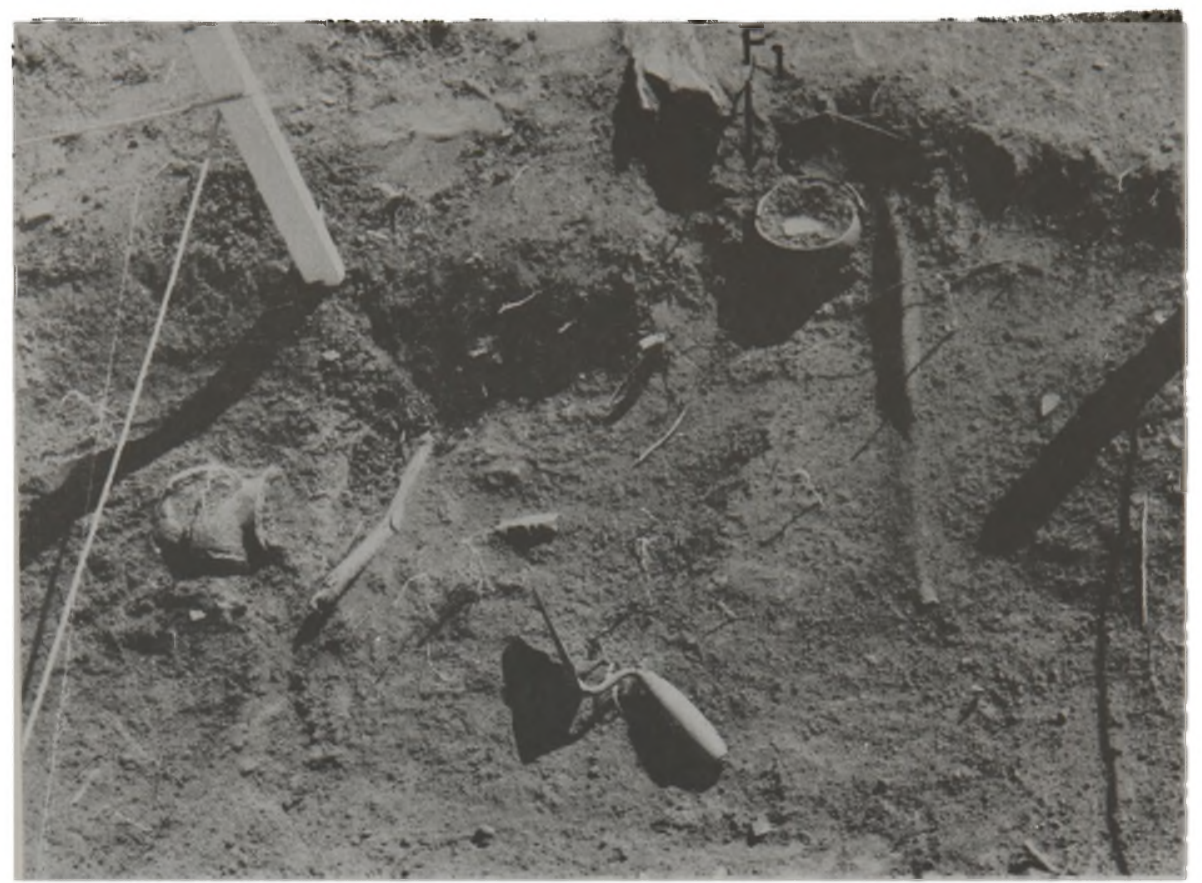

Foto 7 - Sítio SILVA SERROTE - Evidenciação de artefatos cerâmicos lisos, com destaque de um pequeno pote, fragmentado, sobre a Fogueira.

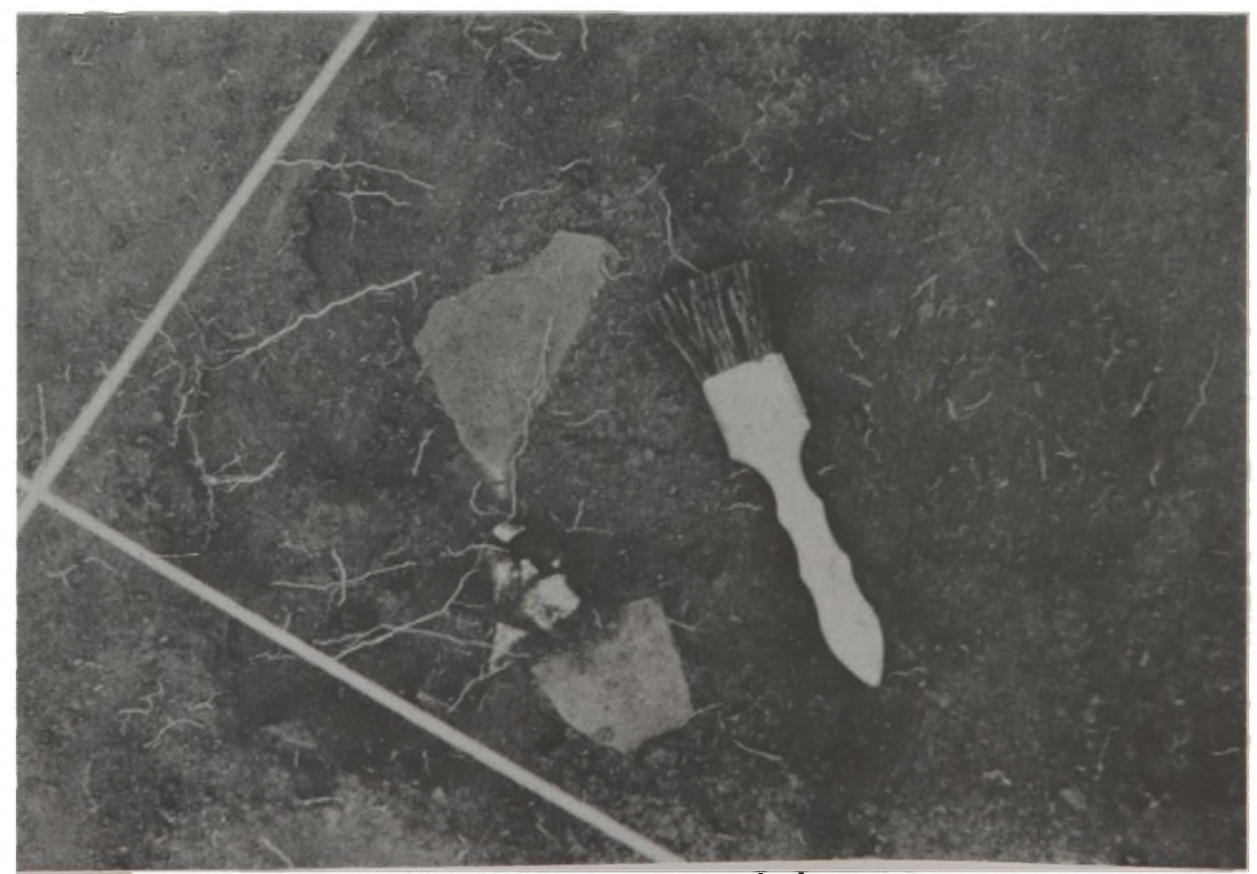

Foto 8 - Sítio PRADO - Núcleo em quartzo remontável com quatro peças, evidenciado na Mancha . 
ALVES, M. A. As estruturas arqueológicas do Alto Paranaiba e Triàngulo Mineiro - Minas Gerais. Rev. do Museu de Arqueologia e Etnologia, S. Paulo, 2:27-47, 1992.

uma fogueira), Silva Serrote $\left(M_{1}-P_{1}-B_{1}\right)$ e Rezende, Zona $_{1}$ - nivel lito-cerâmico, junto à Mancha $_{5}-B_{1}$ (Mapas 2, 3 e 8).

- de POLIMENTO - ocorrência de artefatos polidos - lâminas de machado polidas, almofarizes, mãos-de-pilão, afiadores, polidores, evidenciados nos espaços habitacionais (Manchas Escuras) e de circulaçāo - nivel litocerâmico (Foto 6)

- de CONCENTRAÇĀO DE CERÁ-

MICA - detectada nas seguintes situações:

- Estruturas Habitacionais:

- evidência de concentraçōes de fragmentos de cerâmica junto a fogueiras circulares internas às "Manchas Escuras";

- evidenciação de fragmentos de cerâmica no interior das habitações sugerindo uso no cotidiano cuja remontagem é feita em campo, concomitantemente à escavaçāo (Foto 9).

No sítio Silva Serrote foi evidenciado um pequeno pote junto à Man- cha $_{1}$ - Fogueira, fragmentado mas restaurado em campo, cujo carvāo possibilitou a datação deste sítio (Mapa 3), (Foto 7);

Nos sítios Prado, Silva Serrote, Inhazinha e Rodrigues Furtado foram coletados fusos perfurados nas manchas escuras e nos espaços de circulação (Foto 10).

- Espaços de circulação: no sítio Prado foi detectado e evidenciado na trincheira 4 um vaso de tamanho médio, sobre a Fogueira ${ }_{2}$ e associado a residuos de lascamento em quartzo.

Nele, também, foi evidenciado um vaso no $\mathrm{P}_{3}$, executado junto à Mancha $_{6}$ (Foto 1).

No sítio Inhazinha foi evidenciado um pequeno pote na Trincheira ${ }_{3}$, parcialmente fragmentado (Foto 4).

Ocorrència de fragmentos cerâmicos deslocados de seus espaços originais na superfície de todos os seis sítios, devido às aragens do solo.

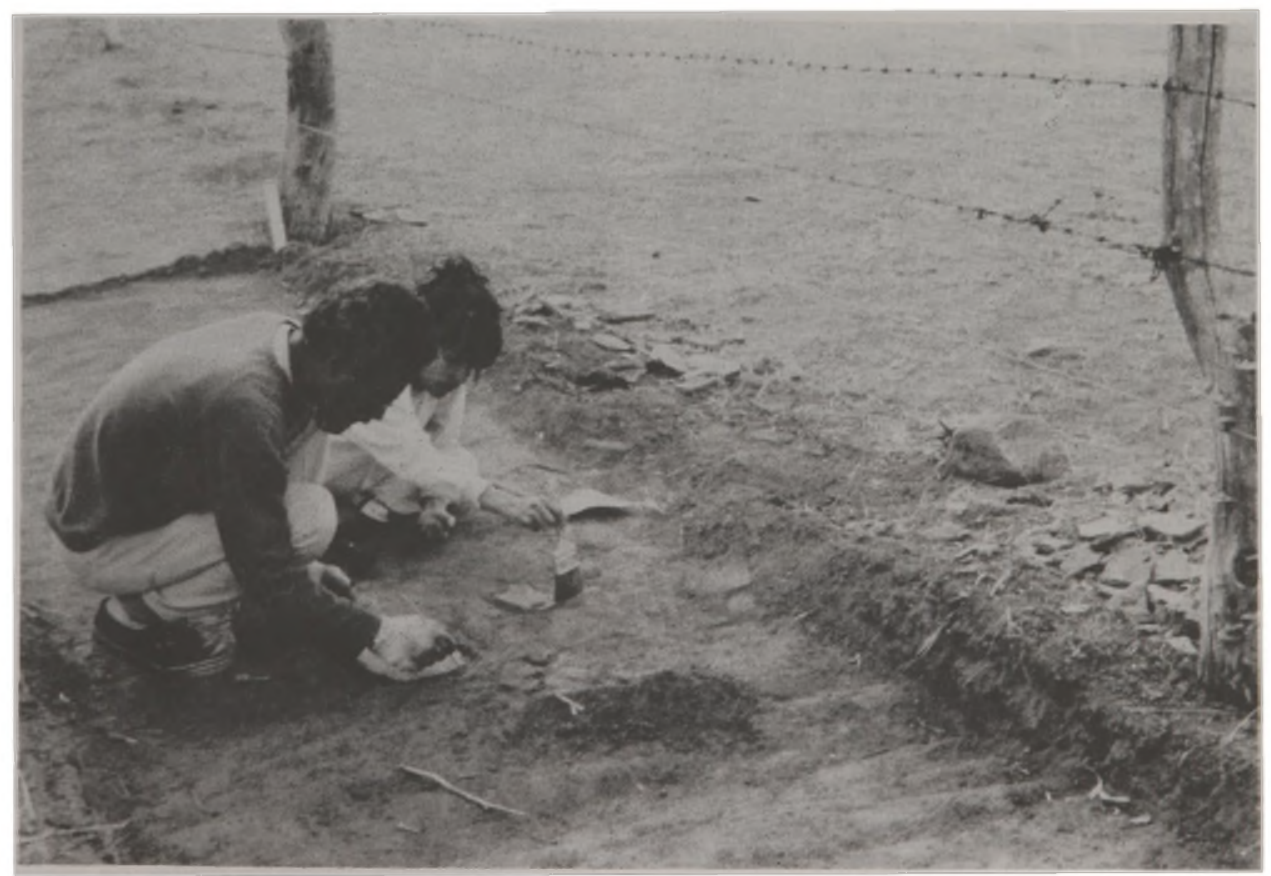

Foto 9 - Sítio MENEZES - Restauração, em campo, de cerâmica fragmentada, concomitantemente à escavação. 


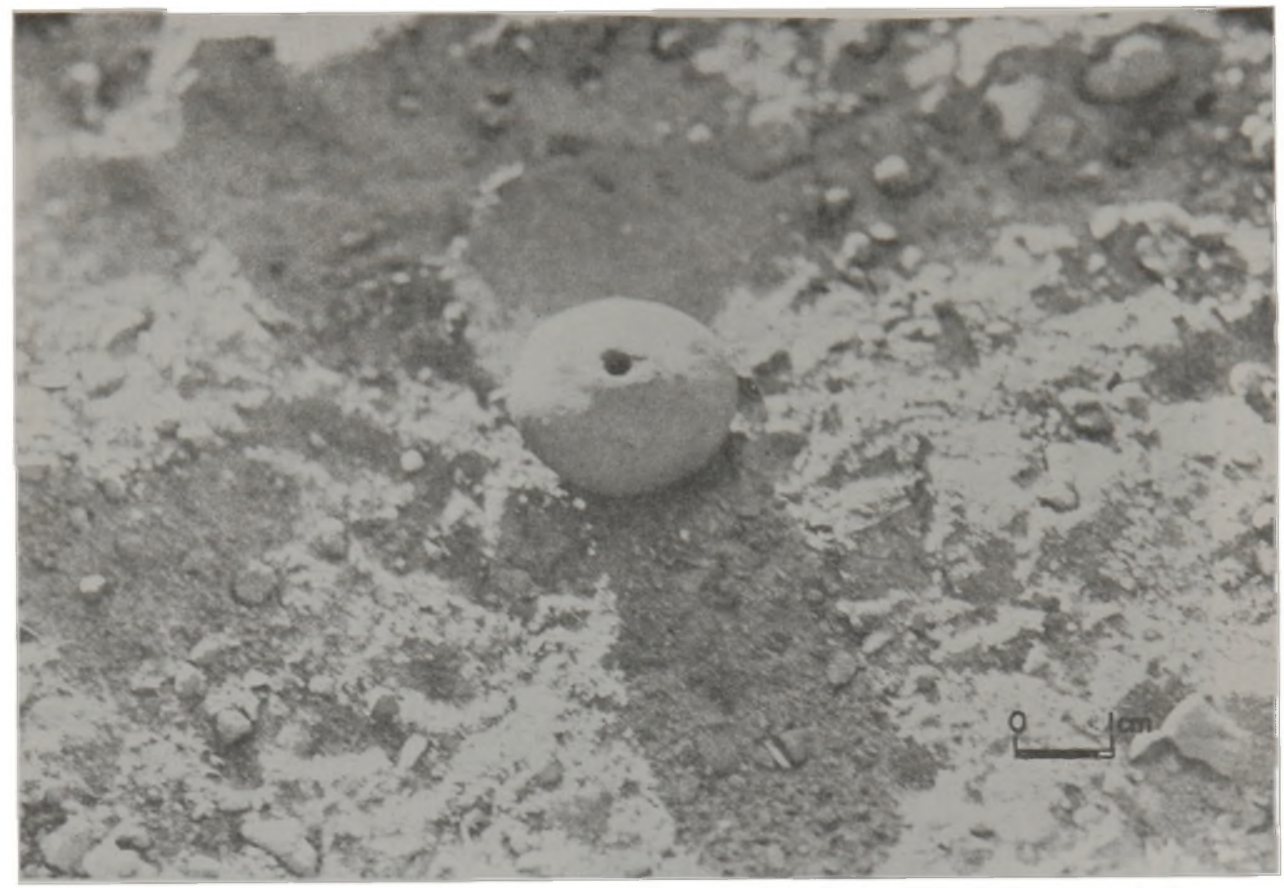

Foto 10 - Sítio INHAZINHA - Coleta de fuso perfurado na Trincheira ${ }_{2}$ que indica, por comparação etnográfica, fiação e tecelagem (fibras vegetais).

\section{Considerações finais}

A apresentação, neste artigo, de resultados de pesquisa em Arqueologia Pré-Histórica no Brasil, desenvolvida no vale do Paranaiba, Minas Gerais, pelo Projeto Quebra Anzol, desde 1980, evidencia a diversidade cultural e temporal de populações ceramistas/horticultoras e caçadoras/coletoras que ocuparam as regiões do Alto Paranaiba e Triângulo Mineiro em tempos pré-coloniais, ou seja, de $670 \pm 50$ anos a.P. a $7.300 \pm 80$ anos antes do Presente - populações extintas e sem escrita.

Assim, é somente pela pesquisa de campo em Arqueologia pré-histórica que é possivel evidenciar os padrões de assentamento; reconstituir o(s) modo(s) de vida e coletar de maneira criteriosa a cultura material de populações pregressas e extintas para a realização de estudos sobre o passado, isto é, a(s) cultu$\mathrm{ra}(\mathrm{s})$ dos primeiros habitantes do vale do $\mathrm{Pa}$ ranaiba.

Nas pesquisas de campo - processadas pelas escavaçōes - é fundamental o emprego de método eficiente que possibilite a identificação da estratigrafia de depósitos de culturas extintas e uma visão do solo arqueológico de cada camada para, em seguida, estudar os vestígios em laboratório a niveis tecnotipológicos.

Os dados obtidos em doze anos de empreendimento de escavações no vale do Paranaiba possibilitaram e possibilitam as seguintes consideraçōes:

- o estabelecimento de populações ceramistas e liticas (pré-ceramistas) em sitios abertos, em meias encostas de colinas e de chapadão, próximas a fontes de água - representa um padrão de assentamento de populaçōes extintas;

- as ocupaçōes ceramistas tinham o dominio do fogo, evidenciado pela queima de utensilios de ceràmica. Deviam utilizá-lo também para iluminar e aquecer as habitações e para cozinhar os alimentos;

- retiravam argila de fontes de matériaprima próximas aos sítios (junto aos barrancos de córregos e rios) para con- 
feccionar cerâmica. Empregavam a técnica ACORDELADA na montagem de artefatos cerâmicos, faziam uma cerâmica LISA, UTILITÁRIA e FUNERÁRIA. Desconheciam o polimento de superficies cerâmicas. Empregavam apenas o ALISAMENTO (Alves, 1988; 1991b);

- as populações ceramistas praticavam uma agricultura incipiente - HORTICULTURA - como indicam, indiretamente, os artefatos líticos polidos: almofarizes, mãos-de-pilão e lâminas de machado polidas.

Deviam ser semi-nômades como indicam as atividades sociais mais expressivas: confecção de cerâmica e horticultura;

- as populações ceramistas viviam em cabanas ovaladas que formavam verdadeiras aldeias;

- enterravam os seus mortos em posição fetal em urnas de cerâmica com tampa, como indicam os sepultamentos detectados nos sítios Silva Serrote e Inhazinha. Também usavam o sepultamento em decúbito lateral esquerdo, como atesta o evidenciado no sítio Rezende (Zona ${ }_{2}$ );

- as populaçōes ceramistas deviam utilizar as fogueiras para queimar artefatos cerâmicos, cozinhar os alimentos, iluminar as habitaçōes e aquecer blocos de pedra para a debitagem;

- os fusos perfurados detectados sugerem, por comparação etnográfica com os Kaiapó Setentrionais, fiação e tecelagem (de fibras vegetais - que desapa- recem em pouco tempo devido ao clima tropical do Brasil);

- os ceramistas praticavam o lascamento da pedra. Dominavam o polimento. Nas ocupaçōes lito-cerâmicas o advento da cerâmica coincide com o do polimento. Os artefatos líticos, lascados e polidos, eram empregados para cortar, perfurar, raspar, amassar, etc.

As ocupaçōes liticas superpostas detectadas no sitio Rezende - duas na Zona ${ }_{1}$ e quatro na Zona ${ }_{2}$ - representam ocupaçōes de populações de caçadores-coletores, nômades, que viviam da caça, coleta e pesca.

Praticavam o lascamento da pedra. Lascavam blocos em quartzo, arenito, arenito silicificado e sílex, utilizando afloramentos rochosos próximos e distantes do sítio Rezende. Tinham técnicas aprimoradas de retoques.

Deviam mudar de habitat com frequência, provavelmente utilizavam a bacia do Paranaiba para realizá-lo.

Os caçadores-coletores que viveram no sítio REZENDE na fazenda PAIOLÄO entre $4.250 \pm 50$ anos a.P. a $7300 \pm 80$ anos antes do Presente, representavam os PRIMEIROS e os mais ANTIGOS habitantes do Triângulo Mineiro.

Assim, o sitio REZENDE é um dos sitios arqueológicos com depósitos de ocupaçōes liticas dentre as mais antigas do Estado de Minas Gerais e com depósitos de culturas de caçadores-coletores mais antigos do Triângulo Mineiro e Alto Paranaiba.

As informações obtidas em doze anos de pesquisas atestam a importância da Arqueologia pré-histórica no Vale do Paranaiba, regiōes do Alto Paranaiba e Triângulo Mineiro. 


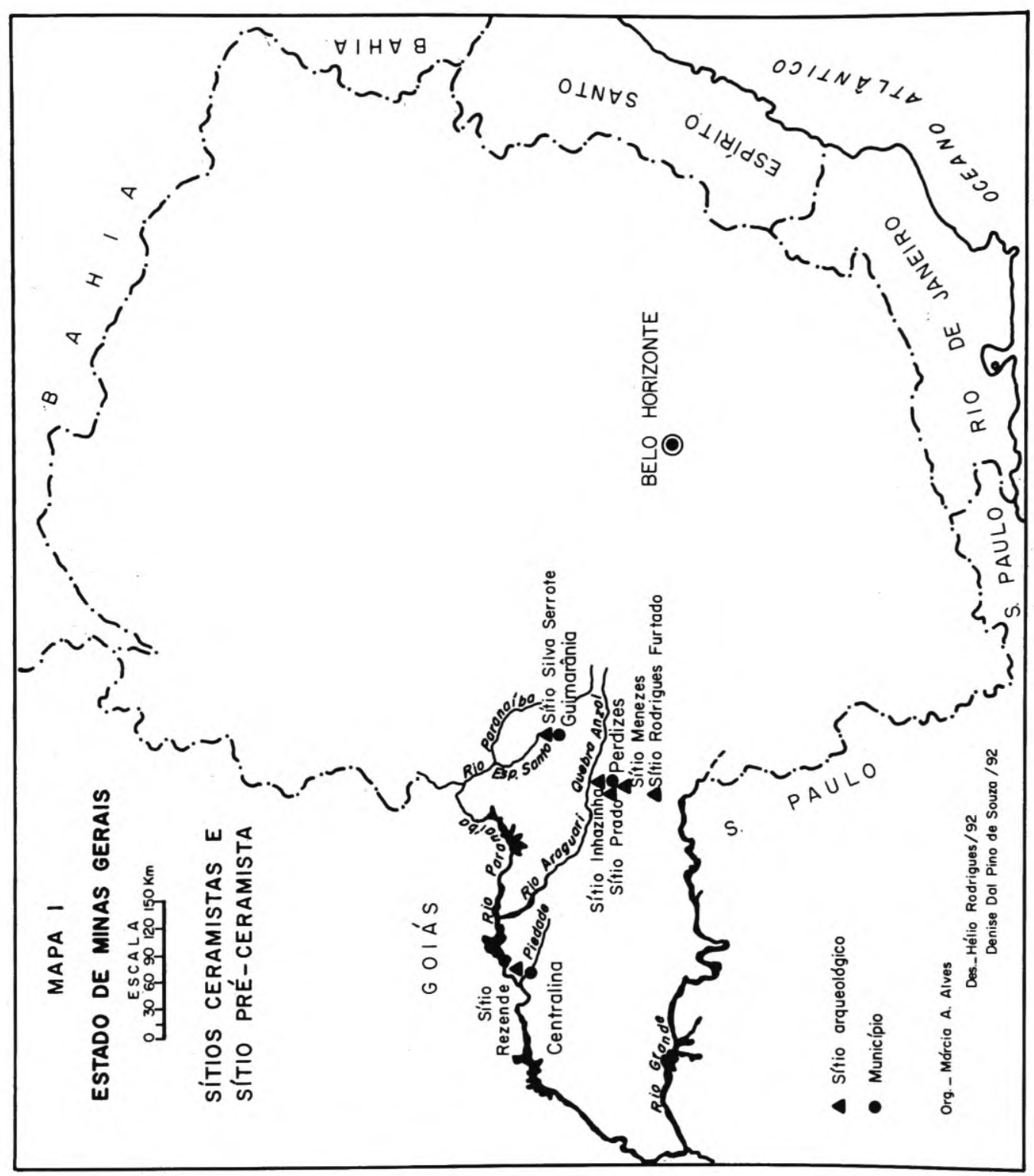


ALVES, M. A. As estruturas arqueológicas do Alto Paranaiba e Triângulo Mineiro - Minas Gerais. Rev. do Museu de Arqueologia e Etnologia, S. Paulo, 2:27-47, 1992.

mapa 2 Sítio Prado-Municipio Perdizes - MG.

Panorama das Escavaçōes - aldeia pré-histórica_ 1980/81/83

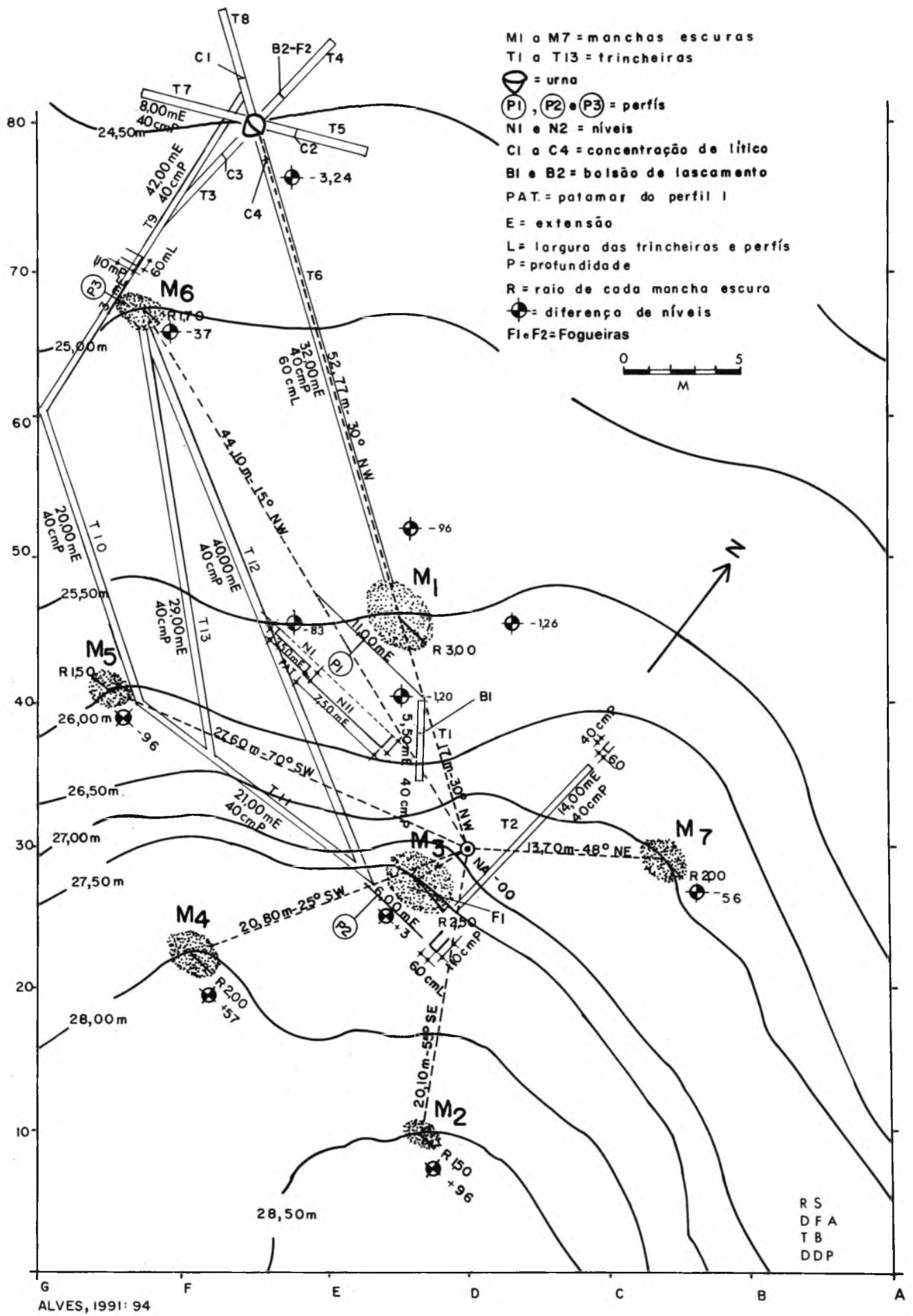


ALVES, M. A. As estruturas arqueológicas do Alto Paranaiba e Triângulo Mineiro - Minas Gerais. Rev. do Museu de Arqueologia e Ernologia, S. Paulo, 2:27-47, 1992.

SÍtio Silva SERROTE - MU N I C I PIO de guimarânia-m.g. MAPA 3 PANORAMA DAS ESCAVACÖES - aldeia pré-histórica. 1985

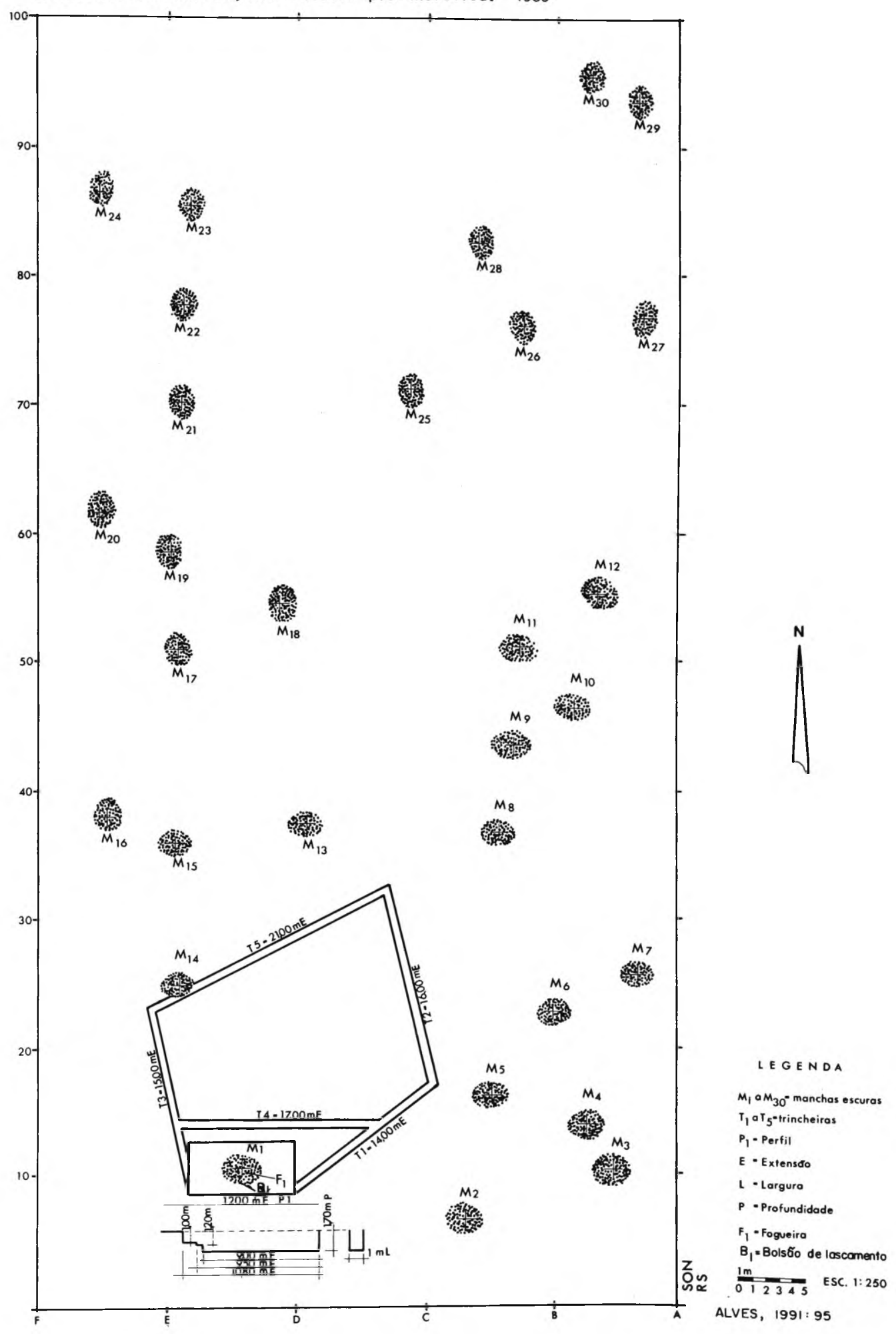


ALVES, M. A. A: estruturas arqueológicas do Alto Paranaiba e Triângulo Mineiro - Minas Gerais. Rev. do Museu de Arqueologia e Etnologia, S. Paulo, 2:27-47, 1992.

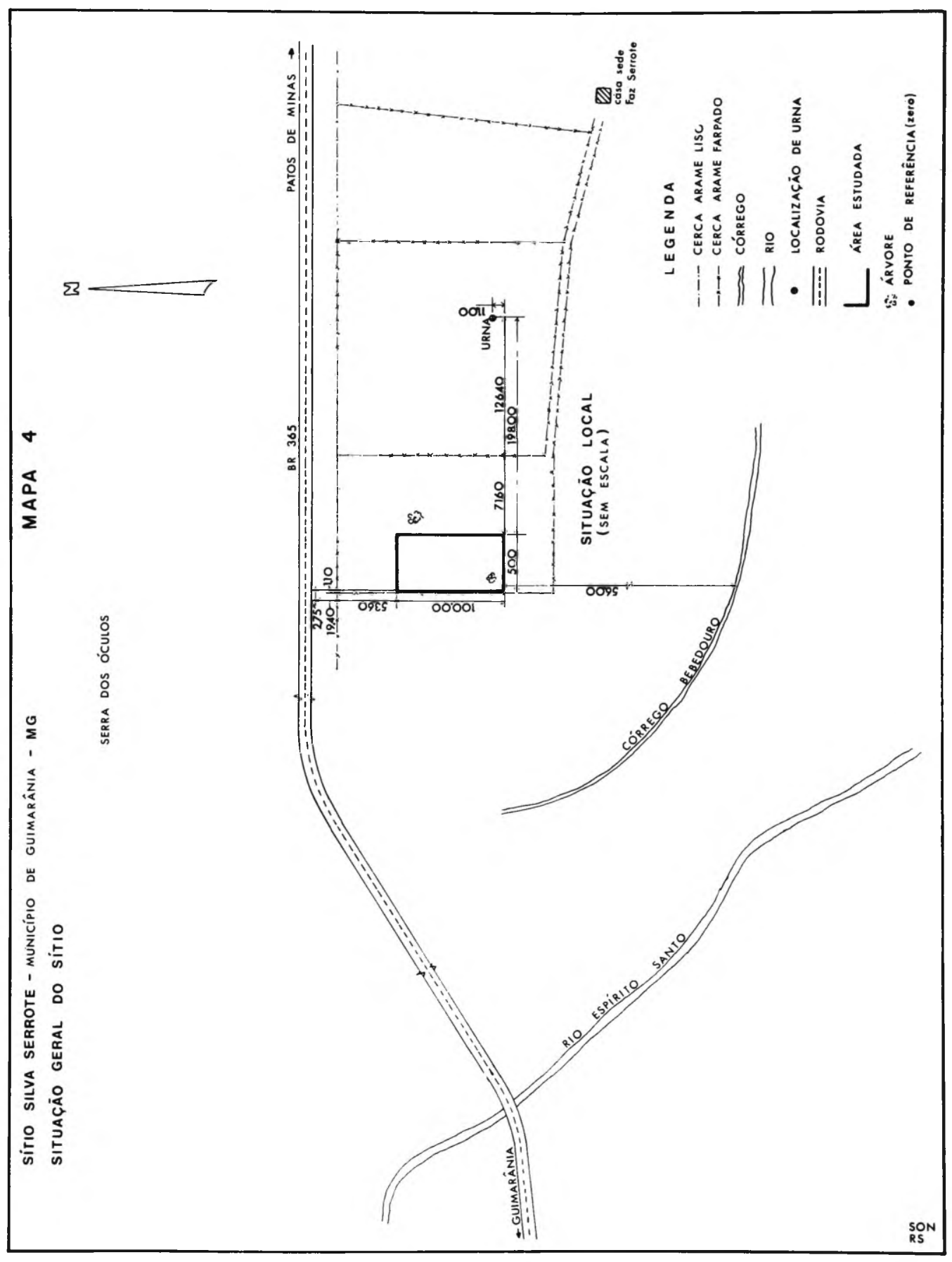


ALVES, M. A. As estruturas arqueológicas do Alto Paranaiba e Triângulo Mineiro - Minas Gerais. Rev. do Museu de Arqueologia e Etnologia, S. Paulo, 2:27-47, 1992.

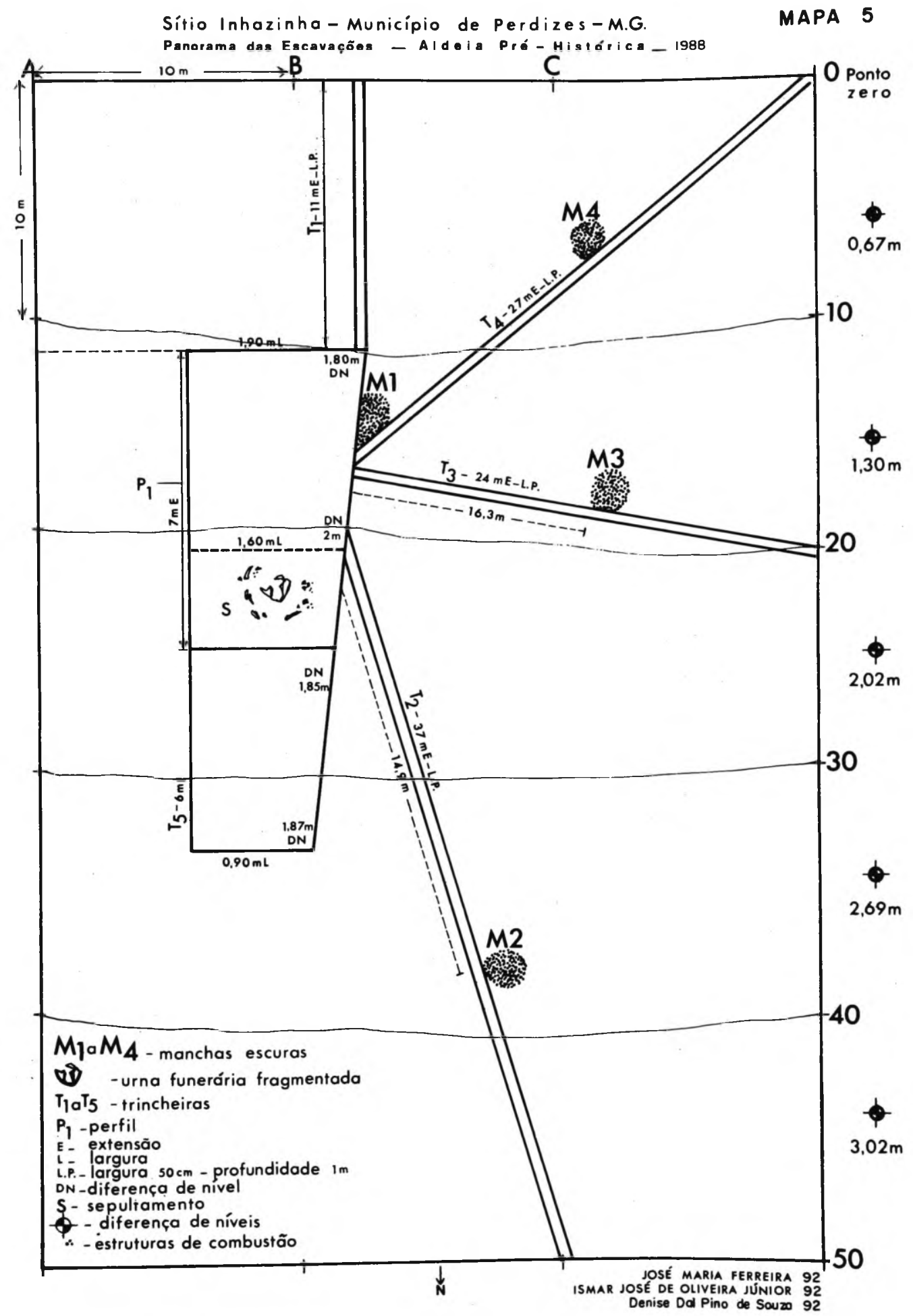


ALVES, M. A. As estruturas arqueológicas do Alto Paranaiba e Triângulo Mineiro - Minas Gerais. Rev. do Museu de Arqueologia e Ernologia, S. Paulo, 2:27-47, 1992.

\section{SITIO MENEZES - MUNICIPIO DE PERDIZES - MG}

Panarama dos escovaçб́es - Aldeia pré-histórica - 1991

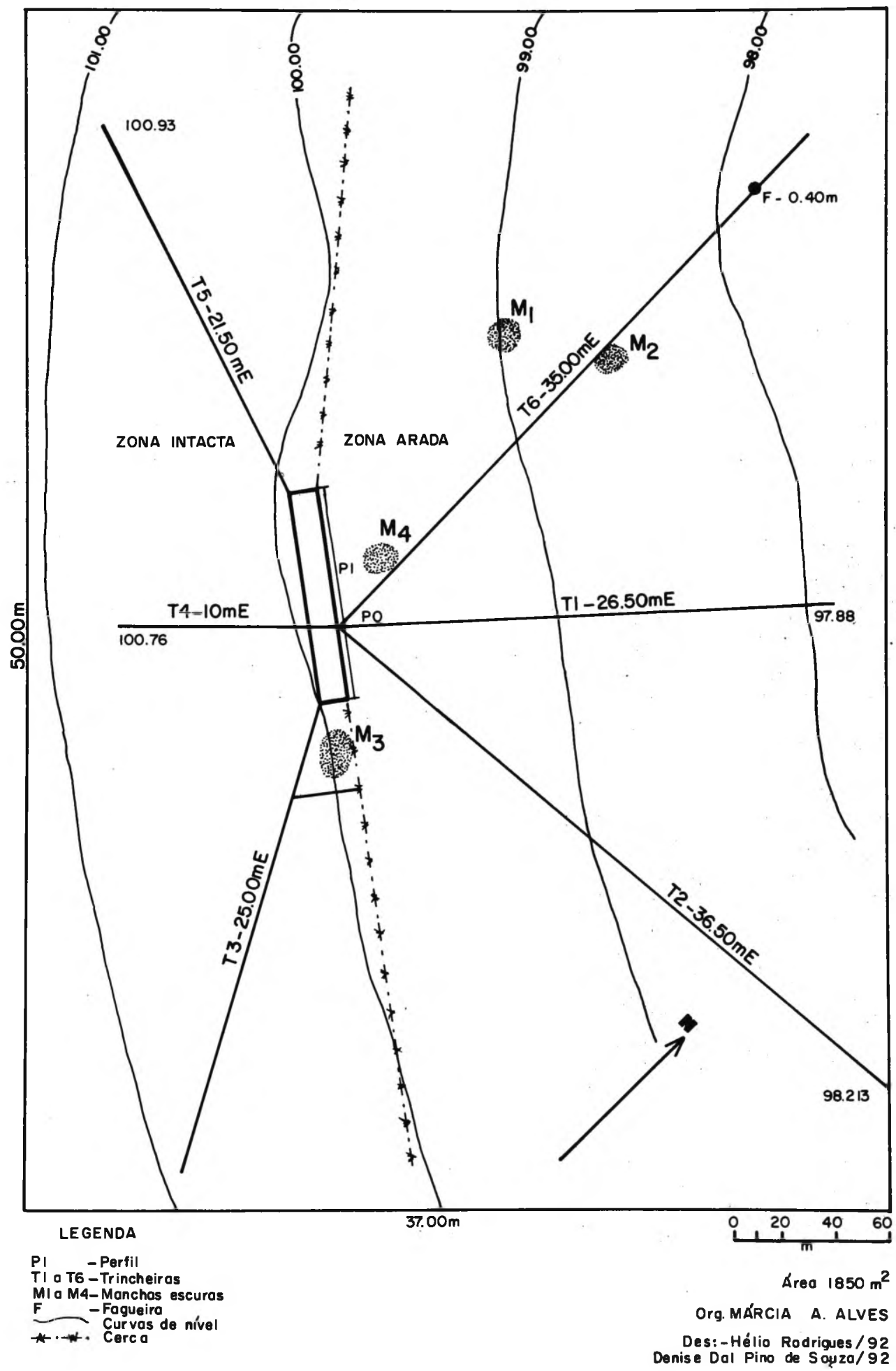


ALVES, M. A. As estruturas arqueológicas do Alto Paranaiba e Triângulo Mineiro - Minas Gerais. Rev. do Museu de Arqueologia e Etnologia, S. Paulo, 2:27-47, 1992.

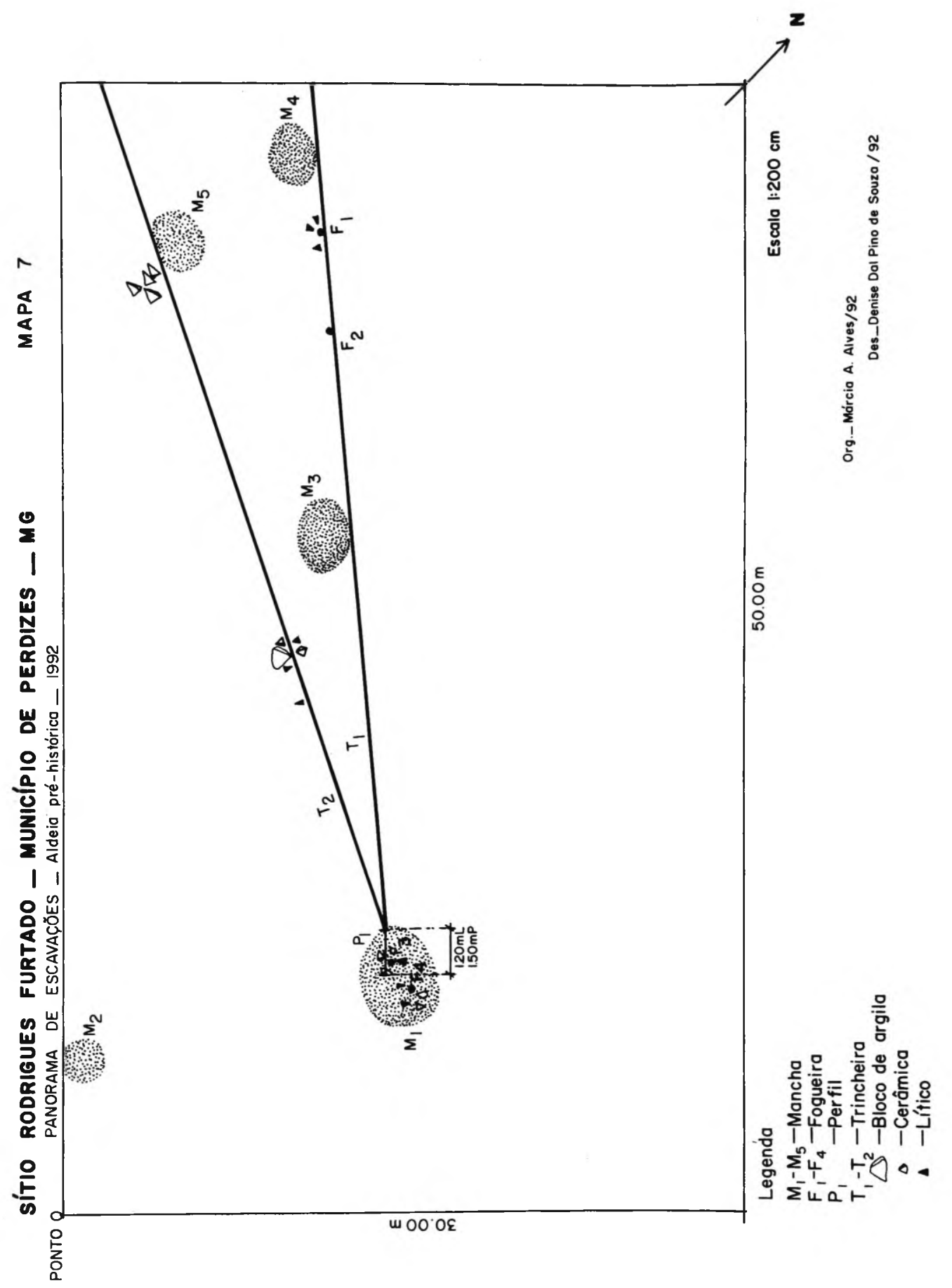


ALVES, M. A. As estruturas arqueológicas do Alto Paranaiba e Triângulo Mineiro - Minas Gerais. Rev. do Museu de Arqueologia e Emologia, S. Paulo, 2:27-47, 1992.

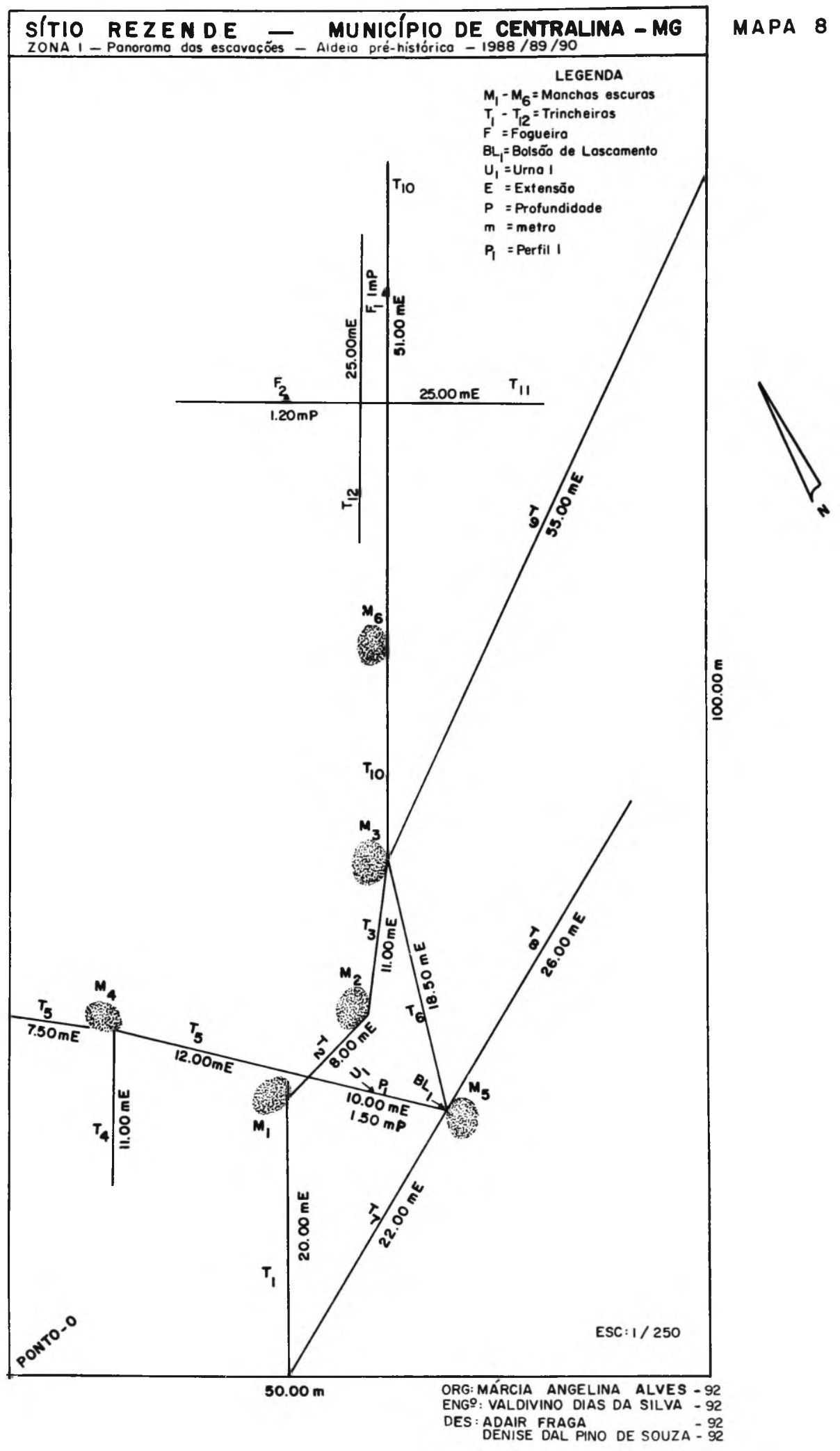


ALVES, M. A. As estruturas arqueológicas do Alto Paranaiba e Triângulo Mineiro - Minas Gerais. Rev. do Museu de Arqueologia e Etnologia, S. Paulo, 2:27-47, 1992.

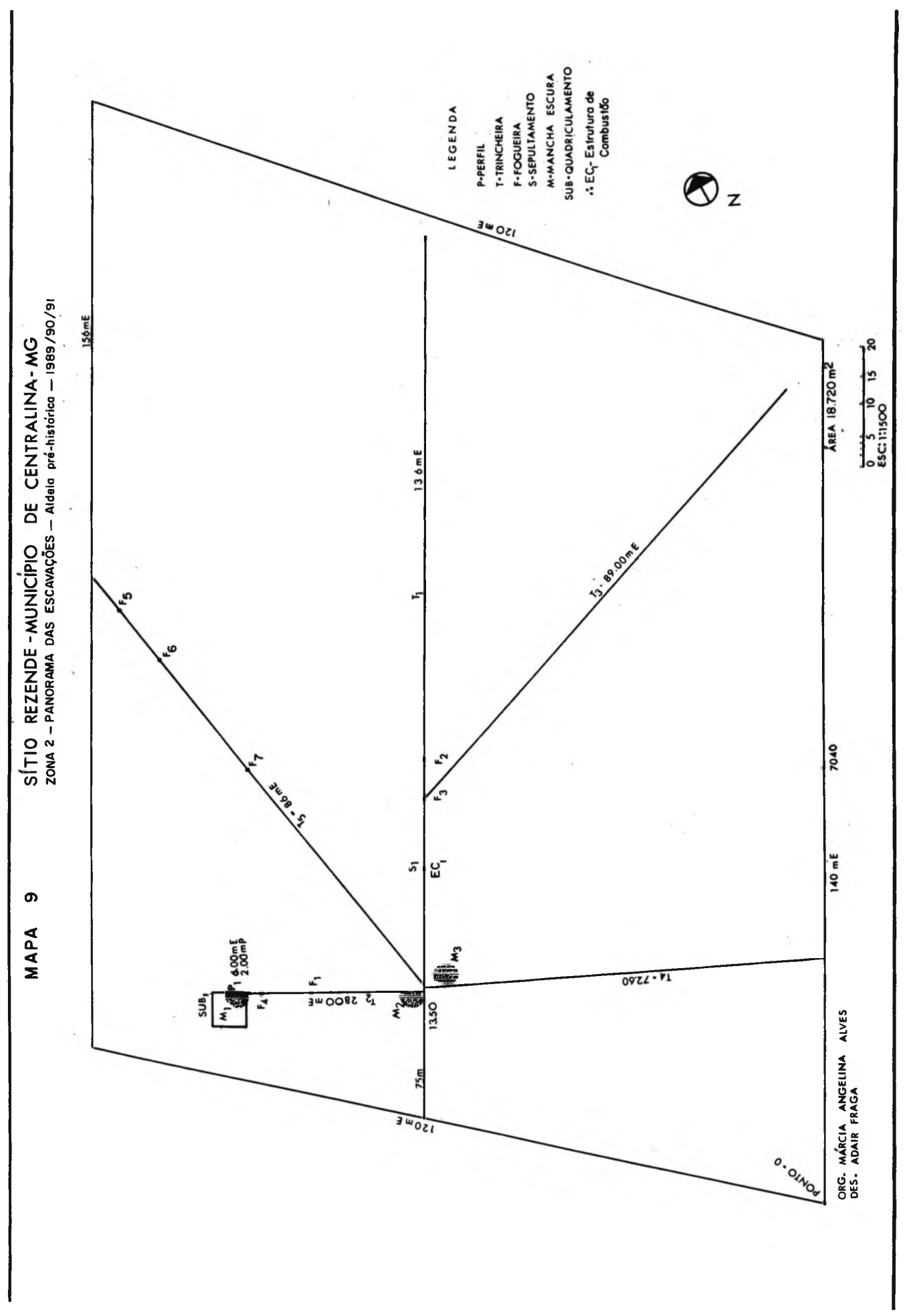

46 
ALVES, M. A. As estruturas arqueológicas do Alto Paranaiba e Triângulo Mineiro - Minas Gerais. Rev. do Museu de Arqueologia e Etnologia, S. Paulo, 2:27-47, 1992.

ALVES, M. A. Archaeological structures of Minas Gerais: the regions of Alto Paranaiba and Triângulo Mineiro. Rev. do Museu de Arqueologia e Etnologia, S. Paulo, 2:27-47, 1992.

ABSTRACT: This paper presents the archaeological structures (associated with stratigraphy and datations) of the regions of ALTO PARANAIBA and TRIÂNGULO MINEIRO, in the state of Minas Gerais, found and excavated in the frame of the prehistory project called "QUEBRA ANZOL", started in 1980. This project comprises a program of systematic PROSPECTIONS AND EXCAVATIONS, which led to the study of six archaeological sites in the last twelve years PRADO, SILVA SERROTE, INHAZINHA, REZENDE, MENEZES e RODRIGUES FURTADO. The aims of the project focus on the evidence of prehistoric settlements in the Paranaiba valley of Minas Gerais.

UNITERMS: Evidences. Stratigraphy. Datations. Structures. Wide surfaces. Settlement patterns.

\section{Referências bibliográficas}

ALVES, M. A. Estudo do sítio Prado - um sítio litocerâmico colinar. Dissertação de Mestrado apresentada no Departamento de História da Faculdade de Filosofia, Letras e Ciências Humanas-USP, 1982. Datilografada.

- Estudo do sítio Prado - um sitio lito-cerâmico colinar. Revista do Museu Paulista. Nova Série, Museu Paulista, USP, XXIX:169-199, 1983/84.

- Análise Cerâmica: Estudo Tecnotipológico. Tese de Doutorado apresentada no Departamento de Antropologia Social da Faculdade de Filosofia, Letras e Ciências Humanas-USP, 1988. Datilografada.

- Projeto Quebra Anzol: evidenciação de ocupações pré-coloniais no vale do Paranaiba, Minas Gerais. Anais da $V^{p}$ Reunião Científica da Sociedade de Arqueologia Brasileira. Universidade Estácio de Sá, Rio de Janeiro, Setembro, 1991a (no prelo).

—. Culturas ceramistas de São Paulo e Minas Ge- rais: Estudo Tecnotipológico. Revista do Museu de Arqueologia e Etnologia. USP, 1:71-96, $1991 \mathrm{~b}$.

ALVES, M. A. e GIRARDI, V. A. V. A confecçāo de lâminas microscópicas e o estudo da pasta cerâmica. Revista de Pré-História, USP, 7:150-162, 1989.

LEROI-GOURHAN, A. Les fouilles préhistoriques technique et méthodes. A. et Picard, Paris, 1950.

- Le fil du temps - Ethnologie et Prehistoire. Fayard, Paris, 1983.

PALLESTRINI, L. Supra-estruturas e infra-estruturas arqueológicas no contexto ecológico brasileiro. Revista do Museu Paulista. Nova Série, Museu Paulista, USP, XX:7-32, 1972/73.

- . Interpretação das estruturas arqueológicas em sitios do Estado de São Paulo. Coleção Museu Paulista, Série Arqueologia, 1, Fundo de Pesquisa do Museu Paulista, USP. Tese de Livre Docência apresentada no Departamento de História da Faculdade de Filosofia, Letras e Ciências Humanas-USP, 1975. 